\title{
A EDUCAÇÃO NOS NOVOS CENÁRIOS ECONÔMICOS E PRODUTIVOS
}

\author{
Vagner Neves Dias
}

RESUMO: O presente trabalho explica os principais indicadores do esforço financeiro que um país realiza em relação à educação; descreve as principais tensões que existem no elo entre a educação e o mercado de trabalho; também apresenta as tendências na educação de jovens na América Latina, especificando se há diferenças entre os países da região; e ainda descreve as principais transformações ocorridas no mercado de trabalho no início do século XXI, exemplificando as mudanças para o caso da América Latina.

Para iniciar, torna-se oportuno mencionar que as tensões econômicas e sociais constituem "o todo das transformações ocorridas no mundo e, refletem-se na constituição da sociedade, alterando as suas relações de poder, convivência e sobrevivência" (SANTOS, 202I, p. I). Assim tem sido desde o século XVIII, período da Revolução Industrial, marcado por fortes alterações nos meios e modo de produção que acabaram por gerar transformações significativas na vida das pessoas em um contexto geral (CAMPOY, 20II).

No decorrer da História, "o capitalismo ao garantir a manutenção do sistema econômico mundial, provoca mudanças profundas na sociedade”, gerando alterações não somente na esfera econômica, mas do mesmo modo no campo da política, da sociedade e

\footnotetext{
${ }^{1}$ Doutor em Ciências da Educação pela Universidad Interamericana - PY (2020). Mestre em Ciências da Educação pela Universidad Interamericana - PY (2018). Licenciado em Química pela Universidade Metropolitana de Santos (2017). Especialista em Metodologia de Ensino de Física e Química pela Faculdade Venda Nova do Imigrante (2015). Licenciado em Matemática através do Programa Especial de Formação de Docente pela Universidade Metropolitana de Santos (2012). Especialista em Educação Matemática com Novas Tecnologias pela Faculdade de Tecnologia e Ciências (2009). Graduado em Ciência da Computação pela Universidade Estadual do Sudoeste da Bahia (2007). Atualmente é professor de Matemática nas séries finais do Ensino Fundamental da Unidade Escolar Municipal Conveniada Gilberto Viana (Prefeitura de Itambé - Bahia), e professor de Ciências e Matemática nas séries finais do Ensino Fundamental da Escola Municipal Naomar Soares de Alcântara (Prefeitura de Itororó - Bahia)
} 
da cultural mundial. Assim são estabelecidas conforme menciona Hobsbawm (1997; 1998; 200I) novas formas de poder, fazendo com que as instituições sociais comecem a apresentar especificidades que conduzem a uma elevação nas tensões sociais que mudam os padrões de comportamento em prol do desenvolvimento capitalista.

A economia mundial na década de 1980 passou por significativas mudanças, e, na América Latina, essas transformações foram ainda mais intensas (BERNARD; JONES, 1995). Depois do processo de precarização do trabalho ocorrida na década de 1990, esses países apresentaram novas conquistas nos níveis de emprego, bem como melhorias nas condições de trabalho (GARCIA, 2014).

Da década de 1990, pode-se chegar ao entendimento de que o paradigma neoliberal se fez presente em quase todos os países latino-americanos. "Desde os anos 70, a ditadura de Pinochet, no Chile, já havia introduzido o receituário neoliberal, porém é no contexto da "crise da dívida" nos países latino-americanos" e depois do Consenso de Washington que tais políticas ganharam força sendo expandidas pelos países do continente (STROMQUIST, 2012).

Passou-se a buscar então novas alternativas para o paradigma neoliberal vivenciada pelos latino-americanos até o final do século $\mathrm{XX}$, momento em que surge a regulamentação do trabalho e debates acerca da sua flexibilização (GARCIA, 2014).

Ocorrendo tantas alterações significantes na estrutura produtiva da economia desses países, se deram concomitantemente mudanças importantes no mercado de trabalho, sendo uma das mais relevantes o fato de o setor de serviços passar a participar na mão de obra empregada em relação aos outros setores da economia, momento em que também se procediam mudanças relevantes na qualificação e especialização da mão de obra (BERNARD; JONES, 1995; ELICABIDE, 2013). É neste ambiente que nasce a chamada profissionalização.

Segundo Tartuce (2006, p. 2):

Com a intensificação da divisão social e técnica do trabalho, acarretada pela revolução industrial, passa-se para um sistema de educação e de formação 
profissional que deveria preparar e socializar o indivíduo para o trabalho (TARTUCE, 2006, p. 2).

Conforme apresentado pelo Panorama Laboral da Organização Internacional do Trabalho (2012), na América Latina, neste período, houvera indicadores do mercado de trabalho mais elevados. A pesquisa apontou que a taxa de desemprego continuava diminuindo e os salários reais aumentavam, havendo progressos na expansão do trabalho formal (ORGANIZAÇÃO INTERNACIONAL DO TRABALHO, 2012).

De uma perspectiva histórica muito geral, pode-se dizer que, antes da era moderna, o trabalho não era apenas uma atividade econômica divorciada de outras esferas da vida social, como a família, a comunidade, o lazer. Nesse contexto, não se preparava o homem para o trabalho; ele aprendia no próprio trabalho (TARTUCE, 2006, p. 2).

No início do século XXI, alguns dos países da América Latina modificaram "sua política econômica com a ascensão de governos de centro-esquerda e de esquerda" (GARCIA; CALVETE, 2015, p. I69). A economia passa então a se fundamentar no conhecimento, o qual assume a função de ser fator determinante na produção de "mudanças socioeconômicas e políticas globais, afetando diretamente os sistemas de bemestar social e do trabalho e, consequentemente, os sistemas educacionais" (ANDRADE; AMARAL, 2012, p. 30).

Porém, a passagem da escola ao trabalho iria depender não somente das capacidades individuais, contudo, também da forma como se organizavam os sistemas educacionais em cenários sociais distintos. "Assim, os vínculos entre escola e trabalho, expressos em diferentes sistemas educativos, podem ser mais fortes ou mais fracos conforme as sociedades" (TARTUCE, 2006, p. 2).

O ideário que circunda a técnica, o saber, a educação e o trabalho, neste início de século técnico-científico-informacional são produzidos por agentes do trabalho no sistema capitalista, e alcançados de maneira imperceptível e instantânea pela sociedade enquanto tentativa de superação ou de construção de outras possibilidades (IBARROLA, 2004). Assim, o planejamento da educação representa um exercício imprescindível para que seja 
mantido ou elevado o crescimento econômico de um país. Conforme citam Nogueira e Nogueira (2002, p. 17):

A educação perde o papel que lhe fora atribuído de instância transformadora e democratizadora das sociedades e passa a ser vista como uma das principais instituições por meio da qual se mantém e se legitimam os privilégios sociais (NOGUEIRA; NOGUEIRA, 2002, p. 17).

Tal afirmativa surge para ratificar o pensamento exposto por Bourdieu (2004, p. II), quando este caracterizou tal fenômeno da seguinte maneira:

[...] Enquanto instrumentos estruturados e estruturantes de comunicação e de conhecimento que os sistemas simbólicos (língua, arte, ciência, religião, cultura etc.) cumprem a sua função política de instrumentos de imposição e de legitimação da dominação, que contribuem para assegurar a dominação de uma classe sobre a outra (violência simbólica) dando o reforço de sua própria força às relações de força que as fundamentam e contribuindo assim, para a "domesticação dos dominados" (BOURDIEU, 2004, p. II).

Nesse diapasão, Nogueira (1990) comenta que é no ambiente escolar que nascem as desigualdades sociais e culturais, sendo a escola uma instituição "a serviço da reprodução e afirmação da dominação e controle das elites, transmitindo uma cultura socialmente reconhecida como autêntica” (SANTOS, 202I, p. I). Para este autor, a Revolução Cultural gerou uma nova compreensão de mundo e de sociedade, o que assegurou "uma ordem internacional injusta e excludente, com a permanência de imensas desigualdades sociais" (SANTOS, 202I, p. I).

Conforme cita Frigotto (2003, p. 32):

O caráter subordinado das práticas educativas aos interesses do capital historicamente toma formas e conteúdos diversos, no capitalismo nascente, no capitalismo monopolista, e no capitalismo transnacional ou na economia globalizada (FRIGOTTO, 2003, p. 32).

Segundo Brito (2021, p. I), "na lógica do capitalismo, as demandas do mercado de trabalho exigem não só uma eficiência material, técnica e objetiva, mas também subjetiva, rápida, criativa e diversificada". Somente desta maneira se manterão "compatíveis com o 
tempo produtivo e financeiro, sendo eles altamente flexíveis e rápidos, características de uma produção flexível e globalizada" (BRITO, 2021, p. I).

A flexibilização dos processos de trabalho segundo Tartuce (2006), acabou demandando além dos conhecimentos técnicos, formais e explícitos, o desenvolvimento de habilidades cognitivas e comportamentais. Significava que não bastava somente isso para atender as necessidades de mercado de trabalhadores especializados, mas sim polivalentes, indivíduos capazes de lidar com tarefas e situações organizacionais e mercadológicas cada vez mais abstratas, complexas e imprevisíveis.

Conforme citam Antunes (1997); Bekerman e Dalmasso (2012), a flexibilização no decorrer do tempo se converteu no capitalismo e no elemento central do mercado de trabalho, proporcionando transformações significativas na forma de inserção na estrutura produtiva e nas formas de representação política, correspondendo tais mudanças a um mundo globalizado no qual impera a capacidade de adaptação dos trabalhadores, a qualidade do trabalho e as novas solicitações do mercado produtivo.

Assim, na compreensão de Lima Filho e Queluz (2005, p. 3):

\begin{abstract}
Considerando a centralidade do trabalho nas dimensões ontológicas e históricas, nas quais se constituem processos contraditórios de construção e de alienação de sujeitos sociais, podemos entender a categoria trabalho como fonte de produção e apropriação de conhecimentos e saberes, portanto, princípio educativo. A educação, tendo o trabalho como princípio educativo [...], é processo histórico de humanização e de socialização competente para participação na vida social e, ao mesmo tempo, processo de qualificação para o trabalho, mediação à apropriação e construção de saberes e conhecimentos, de ciência e cultura, de técnicas e tecnologia (LIMA FILHO; QUELUZ, 2005, p. 3).
\end{abstract}

Mas a educação não protege contra o desemprego. Desse modo, o processo de qualificação necessita ser constante (BOURDIEU, 1987). Assim, como afirmam Andrade e Amaral (2012, p. 32), isto acaba repercutindo "na atuação do poder público sobre a educação e, mais ainda, sobre o processo de transição escola-trabalho de milhares de jovens no mundo", pois, segundo Garcia (2014, p. II), existe "uma relação entre as Estratégias de Desenvolvimento dos países na América Latina e as mudanças no mercado 
de trabalho no início do século XXI". Tal afirmativa se justifica pelo fato de que "os países que mantiveram as políticas neoliberais apresentam piores resultados nas relações de trabalho do que aqueles que buscaram se afastar da doutrina neoliberal" (GARCIA, 2014, p. II).

Para Barroso (2005, p. 726):

[...] na educação, se promovem, se discutem e se aplicam medidas políticas e administrativas que vão, em geral, no sentido de alterar os modos de regulação dos poderes públicos no sistema escolar (muitas vezes com recurso a dispositivos de mercado), ou de substituir esses poderes públicos por entidades privadas, em muitos dos domínios que constituíam, até aí, um campo privilegiado da intervenção do Estado. Estas medidas tanto podem obedecer (e serem justificadas), de um ponto de vista mais técnico, em função de critérios de modernização, desburocratização e combate à 'ineficiência' do Estado ("new public management") [...] (BARROSO, 2005, p. 726).

As consequências de tudo isto para a educação e para o trabalho são notadas quando se verifica que, objetivando o cumprimento de acordos internacionais, os Estados nacionais ratificam a imperatividade de que se minimizem os gastos públicos, especialmente no campo das políticas sociais alcançadas no decorrer do século XX (PICUT, 1999). Importante salientar que estes em geral vivenciam a crise do desemprego, assim como o sobretrabalho, os quais têm sido a mola percussora para o aumento da desigualdade social, do desemprego, da precarização do trabalho, da deterioração dos níveis de renda, de maneira especial entre as faixas etárias mais jovens, produzindo uma massa de excluídos.

A persistência do desemprego que é largamente desfavorável, especialmente nesses países, tem conduzido as segmentações ocupacionais a níveis bem mais elevados, gerando a exclusão dos menos favorecidos economicamente dos empregos nos segmentos educacionais mais elevados, ampliando-se de maneira bastante considerável o processo de discriminação no interior do mercado de trabalho, sobremodo entre as diferentes faixas etárias, entre raças e gênero. 
No que diz respeito à questão do emprego para os jovens, a Organização Internacional do Trabalho (2012, p. I) informa que "74,8 milhões de jovens entre is e 24 anos estavam desempregados em 20II, um aumento de mais de 4 milhões desde 2007 ".

Deve-se reconhecer que o cenário socioeconômico da América Latina gera efeitos adversos às suas possibilidades educacionais, conforme cita o Instituto de Pesquisas Avançadas em Educação:

[...] presentemente, na América Latina e no Caribe há 220 milhões de pessoas vivendo na pobreza.

Um número cada vez maior de pessoas são excluídas dos benefícios do desenvolvimento econômico e social que acompanham a globalização, porque são afetadas por limitações na sua educação que as impede de participar ativamente nesse processo (IPAE, 200I, p. I).

O cenário social exposto pela Organização Internacional do Trabalho, representa a existência de um contexto desafiador (que reflete a visão que a sociedade possui em relação aos jovens), exigindo por parte do poder público rápidas mudanças (modelos de políticas educacionais e de trabalho), tanto no que se refere a requerimentos sociais quanto de trabalho (ANDRADE; AMARAL, 2012).

Contudo, na concepção de Pochmann (2004), essa conjuntura representa uma situação de inatividade forçada que traz à sociedade um novo modo de exclusão advindo do setor educacional, visto que a maioria dos jovens que chegam ao mercado de trabalho na América Latina estão em sua maioria cursando o nível de ensino médio e fundamental, não alcançando o patamar de $20 \%$ os que se encontram cursando o nível superior.

Machado (20II) menciona que esta questão não pode ser analisada e entendida somente mediante uma análise simplista do problema, visto que este é composto por uma engrenagem complexa. A problemática da baixa escolaridade possui componentes históricos marcados pelo crescimento desigual, consequente de riquezas concentradas em mãos de poucos, não distribuída para a maioria que colabora dia a dia com a sua produção.

Assim, comentam Rodriguez (2009, p. 333): 
Políticas fortes de apoio à educação de jovens podem contribuir para a formação de gerações capazes de assumir as rédeas de novos projetos sociais. Por isso, articular políticas de diversos setores e múltiplos atores não é um problema administrativo; implica situar o horizonte que as orienta; é uma decisão de política democrática que é necessário exigir sem minimizar o problema que apresenta em termos de construção de hegemonia. Do mesmo modo, a cooperação internacional tem força quando se articulam projetos macrocoordenados a partir do Estado democrático, a partir do qual se articulam dissensos políticos (RODRIGUEZ, 2009, p. 333).

Para Stromquist (2012, p. 74), “o ensino vem sendo conformado por múltiplas forças, entre as quais, políticas globais de educação, dinâmicas de mercado e apoio reduzido do Estado para provisão da educação”. E, assim, este círculo vicioso tem impossibilitado que a educação mostre o seu poder transformador das relações entre os homens e da agregação de valor à produção; e, nesse cenário de emergência em que vive a sociedade do conhecimento, os requisitos educacionais do emprego aumentam (RUFFIER, 1998).

Para a especialista da UNESCO, Cecília Barbieri, torna-se necessário o estabelecimento de critérios para que se alcance uma educação integral com vistas à cidadania global. Para tanto, torna-se imperativa "uma reavaliação dos desafios da educação e da necessidade de aprimorar sua qualidade". Alcançando-se este patamar, conquistar-se-á uma educação fundada em valores humanísticos, capaz de viabilizar a igualdade, os direitos humanos, a cultura, o respeito, e, principalmente, a identidade dos sujeitos (NOGUEIRA, 2016, p. I).

Segundo UNESCO-CEAAL-CREFAL-INEA (2000), o contexto em que se deve levantar a Educação de Jovens e Adultos (EJA) latino-americanos é radicalmente diferente do que prevalecia na década passada. Pois, hodiernamente vê-se uma sociedade com processos de modernização profundos, cujos setores são incorporados a uma tecnologia moderna, que a coloca no quadro de uma nova sociedade da informação. No entanto, neste processo de modernização fundamentada em uma economia de mercado livre e de reformas, o papel tradicional exercido pelo sistema educacional está levando a uma crescente desigualdade social, gerando assim uma sociedade de grande exclusão, de pobreza 
que revertem para uma crise das políticas sociais redistributivas, e uma relativização à credibilidade dos sistemas democráticos.

Os países latino-americanos estão enfrentando o dilema e o desafio da construção de uma modernidade sem exclusões, para expandir os direitos humanos através de uma educação de qualidade que assegure a todos um sistema democrático modernizador, e políticas sociais eficientes que legalmente reconheçam a diversidade e o multiculturalismo, estabelecendo instituições que promovem a paz, a solidariedade e a não discriminação em razão da etnia ou gênero (UNESCO-CEAAL-CREFAL-INEA, 200o).

O relatório apresentado pela UNESCO da Comissão Internacional sobre Educação para o Século XXI, direcionado especialmente para os latino-americanos, se inicia informando que frente aos muitos desafios dessa nova era, a educação se mostra como um instrumento essencial para o progresso da humanidade, para que esta caminhe em direção aos ideais de paz, liberdade e justiça social. O referido relatório apresenta uma série de "tensões" ou contradições que parecem agravar a situação de toda a humanidade, por exemplo: a tensão entre o global e o local; entre o universal e o singular; entre tradição e modernidade; entre a ação de longo prazo e emergências de curto prazo; entre a competição individualista e oferta de igualdade de oportunidades para todos; entre o desenvolvimento do conhecimento e do desenvolvimento de capacidades de assimilação dos seres humanos; entre o espiritual e o material (UNESCO-CEAAL-CREFAL-INEA, 200o).

Neste contexto são propostos diversos objetivos, dentre eles o de se buscar uma educação capaz de revalorizar aspectos éticos e culturais de existência; o de ordenar os requisitos ciência e tecnologia; e o de buscar a melhoria no autoconhecimento tanto em relação a ele mesmo, quanto ao ambiente em que ele se desenvolve. Todas essas ações, alcançadas a partir da educação, tornariam possível a cada pessoa desenvolver o seu próprio potencial para agir como um cidadão e como um produtor (ORGANIZAÇÃO DAS NAÇÕES UNIDAS PARA A EDUCAÇÃO, A CIÊNCIA E A CULTURA, 2009). Segundo a UNESCO, só será possível alcançar esses objetivos se a educação for 
concebida como um processo contínuo e duradouro, vez que inclui todos os seres humanos, todas as suas instituições e todos as suas estruturas.

Para Delors et al. (1998) e Bárcena et al. (2008), educação ao longo da vida não é um ideal distante, mas uma necessidade democrática, através da qual se pretende que os indivíduos exercitem sua capacidade em dirigir os seus próprios destinos em um mundo de mudanças aceleradas, acompanhados pela globalização, que é um fenômeno que tende a modificar a relação do homem com tempo e com o espaço. Contudo, uma formação deste tipo só pode ser baseada em sólidos pilares.

Neste âmbito, salienta o Instituto de Pesquisas Avançadas em Educação:

[...] são necessários maiores esforços para proporcionar serviços educacionais de melhor qualidade, buscando atingir a eqüidade, dadas as sérias diferenças que persistem, entre os países e dentro deles. O primeiro estudo comparativo subregional do Laboratório Latino-americano para a Avaliação da Qualidade da Educação (1999) revelou essas diferenças e a importância, em termos de realização no campo educacional, de fatores tais como o profissionalismo e a dedicação dos professores, o ambiente escolar, o nível educacional das famílias e a disponibilidade nas escolas de livros de textos e materiais de ensino. [...] Reconhecemos também que há sinais de esperança de que será possível transformar o potencial da educação em um fator determinante no desenvolvimento humano. A presente culminação de uma fase de crescimento sustentado na expansão dos serviços e na cobertura da educação fundamental, dentro do contexto da busca de uma melhor qualidade e eqüidade, é testemunha de efetivos esforços de cooperação por parte dos governos e entre os países, assim como da crescente participação de novos atores. Há agora um claro reconhecimento da necessidade de promover a educação por toda a vida dentro de ambientes humanos e educacionais múltiplos e interativos, e de atribuir maior importância à questão dos valores. Queremos que a nossa educação se fortaleça mediante uma firme fundamentação na possibilidade do aprender a ser, fazer, conhecer e viver em conjunto, absorvendo ao mesmo tempo como um fator positivo nossa rica diversidade cultural e ética. [...] O Fórum Mundial de Dacar, de abril de 2000, fixou as seis metas de Educação para Todos, abrangendo assim os compromissos assumidos em São Domingo pelos Ministros da América Latina e do Caribe, através do seu Plano de Ação. Os Ministros se comprometeram a fazer com que os Estados trabalhem em conjunto com a sociedade civil nas políticas, estratégias e ações destinadas a alcançar as metas estabelecidas (IPAE, 200I, p. I).

Já se passaram três décadas desde a Conferência Mundial de Educação para Todos EPT (1990), organizada pela UNESCO, em que “os países signatários firmaram um 
acordo para expandir significativamente as oportunidades educacionais para crianças, jovens e adultos até 2015" (TROJAN, 2009, p. I).

Como meio de acompanhar sua evolução no que se refere ao cumprimento dessas metas, diversas pesquisas foram desenvolvidas até o presente momento, como o estudo desenvolvido por Juan Casassus logo no início do século XXI, o qual indicou que tais mudanças foram relevantes e serviram para deixar aparente a complexidade com que se dão as alterações no cenário da educação (CASASSUS, 200I).

Ocorre que este exercício de avaliar o cumprimento dos objetivos traçados na Conferência Mundial de Educação para Todos - EPT (1990) ainda se faz necessário, principalmente para promover a continuidade deste processo avaliativo dessa dinâmica nos países da América Latina (TROJAN, 2009). Foi o que aconteceu no ano de 2000, momento em que se reuniram I64 países no intuito de mensurar os progressos alcançados desde a Conferência Mundial de Educação para Todos, em Jomtien, no ano de 1990.

Segundo Trojan (2009, p. 2), "o financiamento é o principal indicador do esforço de cada governo nacional para ampliar a cobertura e a qualidade da educação". Contudo, afirma Trojan (2010) que a ajuda financeira proveniente das agências multilaterais apresenta não apenas o esforço de cada país em si, porém, ainda, as prioridades determinadas pelas agências para auxiliar no cumprimento da agenda global estabelecida pelos acordos internacionais.

Trojan (2010) afirma também que entre os países que compõem a América Latina e que apresentam dados, Cuba, até o ano de 2oro, foi o país que apresentou índices mais elevados em termos de percentuais de gasto público em PNB. E, nesse mesmo período, o Paraguai aponta os menores. Contudo, os relatórios da UNESCO não apresentam de maneira descriminada o total investido por cada país, não sendo possível o desenvolvimento de um estudo comparativo, uma vez que esse valor encontra-se condicionado por variados fatores, como, por exemplo, "os limites da economia de cada país e a posição da educação no conjunto das prioridades estabelecidas" (TROJAN, 2009, p. 7). 


\section{REFERÊNCIAS}

ANDRADE, Francisca Rejane Bezerra; AMARAL, Marcelo Parreira do. Educação e Trabalho no Século XXI: as condições sociais dos jovens no processo de transição escolaemprego na Alemanha e no Brasil. O público e o privado - № 20 - Julho/Dezembro - 2012.

ANTUNES, Ricardo. ¿Adiós al trabajo? Ensayo sobre las Metamorfosis y el Rol Central del Mundo del Trabajo. Editorial Piedra Azul. San Pablo-Brasil, 1997.

BÁRCENA, Alicia et al. Juventud y cohesión social en iberoamérica: Un modelo para armar. Santiago de Chile: CEPAL, 2008.

BARROSO, João. O Estado, a educação e a regulação das políticas públicas. Educ. Soc., Campinas, vol. 26, n. 92, p. 725-751, Especial - Out. 2005.

BEKERMAN, Marta; DALMASSO, Gonzalo. Estructura industrial y assimetrias de política. Argentina y Brasil, A 20 años del tratado de Asunción. Rev. de economía política de BS. AS.| Año 6 | Vol. II | 2012 | 147-187 | ISSN 1850-6933.

BERNARD, A.B.; JONES, C.I. Comparing apples to oranges: productivity convergence and measurement across industries and countries. American Economic Review 86 (5), I995, p. 1216 - I238.

BOURDIEU, P. A economia das trocas simbólicas. 2 ed. São Paulo: Perspectivas, 1987.

. O poder simbólico. 7 ed. Rio de Janeiro: Bertrand Brasil, 2004.

BRITO, Leonardo Chagas de. A ideologia da qualificação, trabalho e a ampliação do "mercado da educação superior". Disponível em: 〈http://www.unicamp.br/cemarx/anais_v_coloquio_arquivos/arquivos/comunicacoes/gts /sessao2/Leonardo\%20_Brito.pdf $>$. Acesso em: 13 fev. 202I.

CAMPOY, José Manuel Gutiérrez. La Revolución Industrial, causas, desarrollo y consecuencias. CFICO. 13 de agosto de 20Ir. Disponível em: <http://pt.calameo.com/read/oo29r66isaof8d33a5eoa >. Acesso em: io fev. 202I.

CASASSUS, Juan. A Reforma Educacional na América Latina no contexto da globalização. Cadernos de Pesquisa, São Paulo, n.II4, 200 . 
DELORS, Jacques et al. Educação um tesouro a descobrir: Relatório para a UNESCO da Comissão Internacional sobre Educação para o século XXI. São Paulo: UNESCO do Brasil/ MEC, I998. Disponível em: 〈http://dhnet.org.br/dados/relatorios/a_pdf/r_unesco_educ_tesouro_descobrir.pdf〉. Acesso em: 02 abr. 2021.

ELICABIDE, Laura Carla Moisá. Transformaciones en las relaciones laborales Colômbia y Brasil: Entre la flexibilización y la Regulación. In: CONGRESSO LATINOAMERICANO DE ESTUdOS DO TRABALHO, 2013, São Paulo. Anais... São Paulo, 2013.

FRIGOTTO, Gaudêncio. Educação e crise no capitalismo real. São Paulo: Cortez, $5^{\text {a }}$ edição, 2003.

GARCIA, Mariana Hansen. O Trabalho Na América Latina no Início Do Século XXI: Uma comparação entre Brasil, Colômbia e Venezuela. Porto Alegre: Universidade Federal do Rio Grande do Sul, 2or4.

GARCIA, Mariana Hansen; CALVETE, Cássio da silva. Colômbia, Brasil e Venezuela e os impactos no mercado de trabalho. Estudos Avançados. 29 (85), 2015.

HOBSBAWM, Eric. A era das revoluções: Europa, I789-I848. Rio de Janeiro: Paz e Terra, 1997.

A era do capital: 1848-1875. 8 ed. Rio de Janeiro: Paz e Terra, 200I.

Letras, 1998.

A era dos extremos: o breve século XX, 1914-199i. São Paulo: Companhia das

IBARROLA, María de. Paradojas recientes de la educación frente al trabajo y la inserción social. Buenos Aires: Redetis, 2004.

IPAE. Instituto de Pesquisas Avançadas em Educação. A Educação na América Latina. 6 de março de 200I. Disponível em: 〈http://www.ipae.com.br/pub/pt/re/ae/

90/materia8.htm>. Acesso em: 02 mar. 202I.

LIMA FILHO, Domingos Leite; QUELUZ, Gilson Leandro. A tecnologia e a educação tecnológica - elementos para uma sistematização conceitual. In: Educação \& Tecnologia. Revista do Centro Federal de Educação Tecnológica de Minas Gerais, v. ıo, n. I, jan./jun. 2005, p.19-28. 
MACHADO, Maria Margarida. A educação de jovens e adultos no século xxi - da alfabetização ao ensino profissional. Inter-Ação, Goiânia, v. 36, n. 2, p. 393-412, jul./dez. 2011 .

NOGUEIRA, C. M. M.; NOGUEIRA, M. A. A sociologia da educação de Pierre Bourdieu: limites e contribuições. Revista Educação e Sociedade, São Paulo, ano 23, n. 78, p. $15-36$, abr. 2002.

NOGUEIRA, M. A. A sociologia da educação do final dos anos 60 e início dos anos 70: o nascimento do paradigma da reprodução. Revista Em Aberto, Brasília, ano 9, n. 46, abr./jun. 1990.

NOGUEIRA, Pedro Ribeiro. UNESCO: "Educação do séc. XXI deve preparar jovens para mudanças globais". 12 de maio de 2016. Disponível em: 〈http://portal.aprendiz.uol.com.br/2016/o5/12/unesco-educacao-sec-xxi-deve-prepararjovens-para-mudancas-globais/>. Acesso em: 15 mar. 2021.

ORGANIZAÇÃO DAS NAÇÕES UNIDAS PARA A EDUCAÇÃO, A CIÊNCIA E A CULTURA. Resumo: Relatório Mundial da UNESCO/Investir na diversidade cultural e no diálogo intercultural. 2009. Disponível em: 〈https://unesdoc.unesco.org/ark:/48223/pfoooor84755_por〉. Acesso em: i9 abr. 2021.

ORGANIZAÇÃO INTERNACIONAL DO TRABALHO. Tendências Mundiais de Emprego 2012. Disponível em: 〈http://www.oitbrasil.org.br/content/tend-nciasmundiais-de-emprego-2012>. Acesso em: 12 fev. 2021.

PICUT, P. Da ciência da educação à sociologia da educação. In: AVANZINI, G. A pedagogia atual: disciplinas e práticas. São Paulo: Edições Loyola, 1999.

POCHMANN, Marcio. Educação e trabalho: como desenvolver uma relação virtuosa? Educ. Soc., Campinas, vol. 25, n. 87, p. 383-399, maio/ago. 2004.

RODRIGUEZ, Lidia Mercedes. Tradução: Beatriz Cannabrava. Educação de jovens e adultos na América Latina: políticas de melhoria ou de transformação; reflexões com vistas à VI CONFINTEA. Revista Brasileira de Educação. v. I4 n. 4I maio/ago. 2009.

RUFFIER, J. La eficiencia productiva: cómo funcionan las fábricas. Montevideo: Cinterfor, 1998.

SANTOS, Flávio Reis dos. As Transformações sofridas pela Família e pela Escola no Mundo Contemporâneo. Disponível em: 
〈http://meuartigo.brasilescola.uol.com.br/educacao/as-transformacoes-sofridas-pelafamilia-pela-escola.htm>. Acesso em: ro fev. 2021.

STROMQUIST, Nelly P. Educação Latino-Americana em Tempos Globalizados. Sociologias, Porto Alegre, ano I4, no 29, jan./abr. 2012, p. 72-99.

TARTUCE, Gisela Lobo B. P. Da escola ao mercado de trabalho. São Paulo: Fundação Carlos Chagas/Difusão de Ideias. Dezembro de 2006. Disponível em: $\langle$ http://www.fcc.org.br/conteudosespeciais/difusaoideias/pdf/entrevista_ escola_mercado.pdf $>$. Acesso em: 25 fev. 202I.

TROJAN, Rose Meri. Políticas educacionais na América Latina: tendências em curso. Revista Iberoamericana de Educación/Revista Ibero-americana de Educação ISSN: I68I5653 n. ${ }^{\circ} 51 / 1-15$ de diciembre de 2009 .

. Estudo comparado sobre políticas educacionais na América Latina e a influência dos organismos multilaterais. RBPAE - v.26, n.I, p. 55-74, jan./abr. 2010.

UNESCO-CEAAL-CREFAL-INEA. La educación de personas jóvenes y adultas en América Latina y el Caribe: Prioridades de acción en el siglo XXI. Santiago de Chile, Mayo 2000. 